\title{
REGLAS COMUNES A LAS ENTIDADES LOCALES $\left({ }^{*}\right)$
}

\author{
por \\ Francisco Sosa Wagner \\ Catedrático de Derecho Administrativo
}

SUMARIO: I. FUNCIONAMIENTO: 1. RÉGIMEN DE SESIONES. 2. ADOPCIÓN DE ACUERDOS. 3. El PROBLEMA DE LA LENGUA.-II. RELACIONES INTERADMINISTRATIVAS. EN ESPECIAL, LA IMPUGNACION DE ACTOS, ACUERDOS: 1. FUNDAMENTO. 2. MECANISMOS PREVISTOS EN LA LEY BÁSICA. 3. LA APARICIÓN DEL CONFLICTO: IMPUGNACIÓN DE ACUERDOS Y EJERCICIO DE ACCIONES. 4. ESTATUTO DE SUS MIEMBROS. 5. INFORMACIÓN Y PARTICIPACIÓN CIUDADANAS.

Analizamos aquellas reglas que, aunque pensadas para las Entidades locales territoriales, son, en rigor, comunes a éstas y a las que no gozan de este carácter. Vamos a ver, pues, el régimen general que afecta al funcionamiento, a las relaciones interadministrativas, a la impugnación de actos y acuerdos, al estatuto de sus miembros y a los derechos de información y participación ciudadanas, sin perjuicio de hacer alusión, a lo largo de la exposición, a las singularidades que afectan tan sólo a algunos tipos de Entidades locales.

(') Este artículo corresponde al capítulo $6 .^{\circ}$ del libro del mismo autor, titulado Manual de Derecho local Madrid, Tecnos, 1987. 


\section{FUNCIONAMIENTO}

\section{RÉGIMEN DE SESIONES}

Las sesiones de los órganos necesarios de las Corporaciones locales responden a las siguientes reglas:

Las del Pleno son de tres tipos: ordinarias, extraordinarias y extraordinarias de carácter urgente. Las ordinarias tienen periodicidad fijada por el propio Pleno, respetando el mínimo señalado por la LB (una al trimestre); extraordinarias son aquellas que convoca el Presidente de la Corporación con tal carácter por propia iniciativa o a solicitud de la cuarta parte, al menos, del número legal de miembros de la Corporación y su celebración no podrá demorarse por más de dos meses desde la presentación del escrito de petición; extraordinarias de carácter urgente son las convocadas por el Presidente de la Corporación cuando la urgencia del asunto a tratar no permite respetar la antelación de dos días hábiles (exigida por la LB, art. 46.2. $b$ LB).

La constitución válida del Pleno se producirá cuando exista un tercio del número legal de corporativos, quórum que deberá mantenerse durante toda la sesión, y siempre que asistan el Presidente y el Secretario o sus sustitutos.

De cada sesión se extiende acta, en la que se deben hacer constar los extremos relativos a lugar, fecha y hora, nombre de los asistentes, carácter de la sesión, asuntos, votación, acuerdos y hora en que se levante por el Presidente la sesión (art. 109 ROF).

Las sesiones son públicas, aunque puede acordarse el carácter secreto del debate y votación cuando los asuntos tratados puedan afectar el honor, la intimidad personal y familiar o la propia imagen.

El lugar de celebración de las sesiones es la sede de la propia Corporación (Palacio Provincial, Casa Consistorial), excepto cuando causas de fuerza mayor lo impidan.

Los debates son dirigidos por el Presidente, quien ejerce, además, las funciones de mantenimiento del orden durante las discusiones, que versan sobre dictámenes, proposiciones, mociones, votos particulares, enmiendas, ruegos y preguntas. El dictamen es una propuesta sometida al Pleno tras el estudio del expediente por la Comisión informativa; la proposición es también una propuesta relativa a un asunto del orden del día; la moción es una propuesta, pero referida a un asunto que se incluye en el orden del día por razones de urgencia; el voto particular es la propuesta de modificación de un dictamen formulado por un miem- 
bro que forma parte de la Comisión informativa; enmienda se llama cuando la misma propuesta la formula cualquier miembro de la Corporación; ruego es la formulación de una propuesta de actuación dirigida a alguno de los órganos de gobierno municipal; pregunta es cualquier cuestión planteada a los órganos de gobierno en el Pleno y puede ser oral o escrita.

Por su parte, la Comisión de Gobierno celebra sesiones, como mínimo, cada quince dias, y éstas son también ordinarias, extraordinarias y urgentes. Su funcionamiento se ajusta a lo previsto para el Pleno, con algunas singularidades, como, entre otras, el plazo entre convocatoria y celebración de la sesión (que no puede ser inferior a las veinticuatro horas, excepto en las sesiones extraordinarias y urgentes) y la falta de publicidad de sus sesiones, aunque los acuerdos deben remitirse a las Administraciones del Estado y Comunidad Autónoma (en el Reglamento debería decir "y/o a la Comunidad Autónoma»), así como a los corporativos.

La Comisión Especial de Cuentas, órgano necesario (art. 119 LB) según nos consta, se rige, en cuanto a su funcionamiento, por lo previsto para las Comisiones informativas (art. 134 y sigs. ROF).

El funcionamiento de los órganos complementarios se ajusta a lo previsto en el Reglamento orgánico o los acuerdos que, al efecto, tome el Pleno; los artículos citados 134 y siguientes ROF completan el régimen de las sesiones, que es desplazable por el Reglamento orgánico según la regla cuyo contenido ya conocemos.

Las Mancomunidades acomodan su funcionamiento a las normas previstas para el Pleno del Ayuntamiento; las Comunidades de Villa y Tierra, a sus normas consuetudinarias o a lo dispuesto en sus Estatutos; las Juntas vecinales, a lo previsto para la Comisión de Gobierno; para los Municipios que funcionan en régimen de Concejo abierto, éste se ajustará a los usos y costumbres tradicionales o a las leyes de las Comunidades Autónomas sobre régimen local; con carácter supletorio rige el artículo $111 \mathrm{ROF}$ y, en lo posible, lo previsto para el funcionamiento del Pleno.

\section{ADOPCIÓN DE ACUERDOS}

Se adoptan por mayoría simple de los miembros presentes, lo que se produce cuando los votos afirmativos son más que los negativos. Algunos asuntos exigen mayorías cualificadas (la enumeración se contiene en el artículo 47.2 y 3 LB que, por su carácter básico, no puede ser 
ampliado por las normas de las Comunidades Autónomas): mayoría absoluta del número legal de miembros de la Corporación o de las dos terceras partes del número de hecho. Mayoría absoluta se produce cuando los votos afirmativos son más de la mitad del número legal de miembros de la Corporación. La mayoría de las dos terceras partes se produce cuando los votos afirmativos igualan o superan a los dos tercios del número de hecho de miembros que integran la Corporación, excepto en el caso de la constitución en Concejo abierto de algunos Municipios (art. 29.1.b LB), supuesto en el que la mayoría de dos tercios se refiere al número legal de miembros de la Corporación (art. 99 ROF).

Las votaciones pueden ser ordinarias, cuando se manifiestan por signos convencionales de asentimiento, disentimiento o abstención; nominales, cuando se realizan mediante llamamiento por nombre y apellidos, y secretas, cuando se realizan por papeleta depositada en una bolsa o urna.

\section{El PROBLEMA DE LA LENGUA}

Según el ROF (art. 86.1 en su versión originaria, no corregida), «las convocatorias de las sesiones, los órdenes del día, mociones, votos particulares, propuestas de acuerdo y dictámenes de las Comisiones informativas se redactarán, en todo caso, en lengua castellana. Se redactarán asimismo en la lengua cooficial en la Comunidad Autónoma a la que pertenezca la Corporación, cuando así lo exija la legislación de la Comunidad Autónoma o lo acuerde la Corporación".

El párrafo segundo de dicho artículo 86, al referirse a los debates, establece que "podrán utilizarse, indistintamente, la castellana o la cooficial...", lo que puede perturbar el desarrollo de las sesiones y provocar situaciones absurdas cuando haya miembros del Pleno que no conozcan -y no están obligados a ello- el léxico y la gramática autóctonos. Los Ayuntamientos, salvo excepciones, carecen de medios suficientes para instalar servicios de traducción simultánea, posibilidad, además, no contemplada en el Reglamento.

Pero no es éste el punto más grave. El párrafo primero del artículo 86; como veíamos, preveía la obligatoria redacción en castellano de determinados documentos (notificaciones de convocatorias, órdenes del día, informes y otros actos de trámite), sin descartar el posible bilingüismo en los mismos, cuando lo exigiera la legislación autonómica o lo acordara la Corporación.

Pues bien, tal precepto fue variado radicalmente por la no por vieja menos ilegal técnica de la corrección de errores, aparecida en el Boletín 
Oficial del Estado de 14 de enero de 1987, y que también afectaría a otro precepto lingüístico (el relativo a las actas y al papel de los Secretarios locales, que veremos más adelante).

De acuerdo con el texto corregido, «las convocatorias de las sesiones, los órdenes del día, mociones-votos particulares, propuestas de acuerdo y dictámenes de las Comisiones informativas se redactarán en lengua castellana o en la lengua cooficial en la Comunidad Autónoma a la que pertenezca la entidad, conforme a la legislación aplicable y a los acuerdos adoptados por la correspondiente Corporación».

Frente al correcto esquema inicial que permitía al Estado salvaguardar la lengua española a reserva de lo que adicionalmente estableciera la Comunidad Autónoma con respecto a la suya, o incluso la propia Corporación, nos hallamos ahora ante una disyuntiva: las convocatorias, informes o propuestas, o se redactan en castellano o en la lengua cooficial. El Estado se retrae en la protección del idioma oficial, pues la "legislación aplicable» (en vez de la mera referencia a la legislación autonómica) es sólo hoy la autonómica, ya que el Estado nada previó al respecto en la legislación local básica, ni, hoy por hoy, existe una Ley general sobre el uso del castellano; hay, en cambio, en cada Comunidad con lengua propia una disposición "normalizadora" que contempla el uso del idioma privativo ante y dentro de todos los Poderes públicos radicados en el espacio regional.

Si el Tribunal Constitucional ha señalado que los expedientes administrativos no pueden seguirse sólo en euskera, aun cuando se hayan iniciado en dicha lengua y se provea de extractos o traducciones castellanas a quien alegue indefensión (Sentencia 82/1986), y también que no cabe primar como auténtico al texto legal en catalán, aunque sea original con respecto a la versión castellana (Sentencia 83/1986), podemos fácilmente intuir la inconstitucionalidad del texto corregido, muy especialmente si lo ponemos en relación con la otra abusiva alteración a la que voy a referirme.

En efecto, también en su versión original, el ROF preveía (en el artículo 110) la forma lingüística de las actas, la aprobación simultánea de las dos versiones y la posibilidad - nada infrecuente tratándose de un funcionario con habilitación nacional- de que el Secretario debiera ser auxiliado ante su posible desconocimiento de la lengua cooficiall.

Este precepto estaba, a su vez, en relación con los artículos 201 y 202 ROF, donde se decía - y se sigue diciendo en contexto bien distintoque "las actas y resoluciones redactadas en versión bilingüe se transcribirán a los libros correspondientes mediante el sistema de doble columna, una para cada lengua, a fin de facilitar su cotejo y usom. 
Resulta así que del complejo formado por los artículos 86.1, 110 y 201, donde se aseguraba siempre una versión castellana, y, por ello, unos libros de actas donde esta lengua, sola o acompañada, siempre estuviera presente, hemos pasado, con la célebre corrección de errores, a otra diametralmente opuesta, donde la lengua española puede quedar ausente. Pues si el artículo 110.1 ROF remitía a la forzosa presencia del idioma común en las actas y hoy sólo remite a la «legislación aplicable», el párrafo 2 de este artículo 110 ROF - bien largo, por cierto- ha desaparecido, como por ensalmo, con la corrección de errores. Es bien cierto que su redacción era mala y abocaba al absurdo, ya que si el Secretario no conocía la lengua regional en la que se celebraban los debates y aprobaciones, ¿cómo iba a levantar actas en castellano que luego fuera traducida por "persona idónea»? Persona que se convertiría, de hecho, en el fedatario local ante la indefensión del funcionario nacional que, al revés de la previsión reglamentaria, debería aguardar una traducción al castellano para estampar, a ciegas, su firma.

La pura supresión de ese párrafo, sin embargo, deja aún más desamparados a los Secretarios, pues, o aprenden necesariamente (no ya como mérito preferente) el segundo idioma, o se va, o se acomodan, en permanente dejación de funciones, a firmar todo lo que, en lenguaje extraño, se les presente.

Es bien cierto que las leyes normalizadoras de las Comunidades Autónomas suelen contener previsiones correctas de bilingüismo en la órbita local y que todas van pasando por el Tribunal Constitucional. Pero, justo por ello, no deja de ser sorprendente que las Comunidades Autónomas sean las que hayan de preocuparse por la suerte de los castellano parlantes cuando ello compete principalmente a los órganos estatales.

\section{RELACIONES INTERADMINISTRATIVAS. EN ESPECIAL, LA IMPUGNACION DE ACTOS, ACUERDOS}

\section{Fundamento}

Las relaciones entre las Administraciones públicas territoriales están presididas, según ya he advertido, por los principios de coordinación y eficacia, como se cuida de subrayar el artículo 55 LB. Precisamente, para hacer realidad tales principios, este precepto formula un mandato que excede del ámbito de las Corporaciones locales para interesar igualmente a las Administraciones del Estado y de las Comunidades 
Autónomas, ya que todas ella, en sus relaciones reciprocas, deben respetar el ejercicio legítimo de sus respectivas competencias, ponderar en sus actuaciones la totalidad de los intereses públicos implicados, facilitar la información necesaria y prestar cooperación y asistencia activas. Ya se ha dado cuenta de las fórmulas de cooperación voluntaria (art. 57 LB) y mediante creación de órganos ad hoc (art. 58 LB), por lo que resta ahora conocer las demás técnicas contempladas en la Ley y, en especial, aquellas que suponen el ejercicio de unas facultades de control de la actividad de los entes locales por los órganos de las Administraciones del Estado y las Comunidades Autónomas, facultades que tienen su justificación «en los distintos niveles del interés general, en función de los cuales han de atribuirse las respectivas competencias" (S.T.C. 22 de diciembre de 1981), y en el hecho de que «autonomía no es soberanía, y dado que cada organización territorial dotada de autonomía es una parte del todo, en ningún caso el principio de autonomía puede oponerse al de unidad, sino que es precisamente dentro de éste donde alcanza su verdadero sentido, como expresa el artículo 2 de la Constitución» (Sent. T. C. 2 de febrero de 1981). Más aún, «la unidad misma del sistema en su conjunto, en el que las diferentes entidades autónomas se integran, así como el principio de eficacia administrativa, que debe predicarse no sólo de cada Administración Pública, sino del entero entramado de los servicios públicos, permiten, cuando no imponen, al legislador establecer fórmulas y cauces de relación entre unas y otras Administraciones locales, y de todos ellos con el Estado y las Comunidades Autónomas, en el ejercicio de las competencias que para la gestión de sus intereses respectivos les corresponden" (Sent. del T. C., de 27 de febrero de 1987).

En la medida en que la Constitución no ha definido cuáles son los mecanismos de control, éstos quedan confiados a la ley, pues es ésta la que fija el contenido de la autonomía local y delimita el derecho local de autogobierno ("es la Ley, en definitiva, la que concreta el principio de autonomía de cada tipo de entes, de acuerdo con la Constitución", Sent. T. C. de 2 de febrero de 1981), que, además, es compatible con la existencia de un control de legalidad sobre el ejercicio de las competencias locales, realizado en los casos y formas predeterminadas por el legislador, por el Estado o por las Comunidades Autónomas, habida cuenta de la posición de superioridad de uno y otros sobre las Corporaciones locales. Bien entendido que nunca podrá tratarse de controles genéricos e indeterminados que sitúan a los entes locales en una posición de subordinación o dependencia cuasi jerárquica respecto de la Administración estatal o autonómica, sino de controles de carácter concreto, 
que habrán de referirse normalmente a supuestos en que el ejercicio de las competencias de la Entidad local incidan en intereses generales concurrentes con los de aquéllas (Sent. 27 de febrero de 1987). Ello es, por lo demás, frecuente en los Ordenamientos comparados, entre los que destaca el alemán federal, por lo depurado y perfilado de sus técnicas, y en donde se contemplan mecanismos que van desde el derecho y el deber de informar a la impugnación de actos y acuerdos con efectos suspensivos, pasando por la ejecución sustitutoria y el envío de comisionados con facultades de inspección en el seno mismo de los órganos locales.

\section{MeCanismos previstos en la Ley BÁSica}

a) Figura en primer lugar el derecho/deber de información, pues «las Entidades locales tienen el deber de remitir a las Administraciones del Estado y de las Comunidades Autónomas, en los plazos y forma que reglamentariamente se determine, copia o, en su caso, extracto comprensivo de los actos y acuerdos de las mismas". Son los Presidentes de las Corporaciones y, de forma inmediata, los Secretarios los responsables del cumplimiento de este deber (art. 56.1 LB). Se puede llegar igualmente a solicitar la exhibición de expedientes y emisión de informes para comprobar la efectiva aplicación de las legislaciones estatal y autonómica. La Ley catalana (de 2 de abril de 1987, art. 130) prevé incluso la elaboración de un plan informático al efecto.

b) El artículo 59 LB, que ya conocemos, diseña un mecanismo de coordinación pensado específicamente para las relaciones entre Comunidad Autónoma y Diputaciones Provinciales, según el cual las leyes del Estado o de las Comunidades Autónomas pueden atribuir al Gobierno de la Nación o al Consejo de Gobierno de la Comunidad Autónoma la facultad de coordinar la actividad de la Administración local y, en especial, de la Provincia; coordinación que ha de hacerse a partir de la aprobación de planes sectoriales donde se contengan los objetivos y prioridades de la acción pública, y que se configuran, así como el marco en el que deberán ejercer las entidades locales sus facultades de programación, planificación u ordenación. Precepto éste claramente pensado para perfilar las facultades de coordinación de las actividades de las Diputaciones Provinciales que a muchas Comunidades Autónomas asiste y que es necesario interpretar de acuerdo con el reciente e importante pronunciamiento del T. C., cuyos términos han quedado examinados (lección $5^{\mathrm{a}}$, a la que me remito). 
c) La ejecución subsidiaria regulada en el artículo 60 tiene un carácter general desconocido en el Derecho local anterior, donde sólo se encontraban figuras análogas en algunos sectores (tal, por ejemplo, el sanitario, art. 428 de la Ley de 1955). De claro origen germánico federal, pues una regla de idéntico contenido aparece en las Gemeindeordnungen de todos los Länder, intenta evitar el incumplimiento por las Corporaciones locales de sus obligaciones legales, con daño para los servicios que el ciudadano recibe. El legislador ha querido, además, evitar la intromisión arbitraria de las Administraciones estatal y autonómica, por lo que ha rodeado la aplicación del precepto de grandes cautelas. En efecto, el supuesto de hecho contemplado, es decir, el incumplimiento de las obligaciones de una Entidad local, sólo se produce cuando tales obligaciones "estén impuestas directamente por la ley y su cobertura económica estuviera legalmente o presupuestariamente garantizada", y, además, tal incumplimiento afecte al ejercicio de las competencias de las Administraciones superiores. Sólo, pues, en estos casos, están las Administraciones del Estado y de la Comunidad Autónoma, según sus respectivas competencias, autorizadas para recordar a la Entidad local el cumplimiento de la obligación incumplida; transcurrido el plazo otorgado (nunca inferior a un mes) y si el incumplimiento persiste "se procederá a adoptar las medidas necesarias para el cumplimiento de la obligación a costa y en sustitución de la Entidad local». El precepto es importante, pues en un sistema como el diseñado por la nueva legislación local, donde los controles han quedado reducidos al mínimo, puede una regla como la descrita jugar un papel relevante.

d) Los entes locales deben tener asegurada su participación o integración en aquellas actuaciones o procedimientos cuya decisión final corresponde al Estado o a la Comunidad Autónoma cuando se trate de actividades cuya naturaleza "haga muy difícil o inconveniente una asignación diferenciada y distinta de facultades decisorias» (art. 62 LB). El precepto, animado de la mejor intención, necesita, como él mismo invoca, su desarrollo en la legislación sectorial y de las Comunidades Autónomas (la Ley catalana de 2 de abril de 1987 no prevé la audiencia y la emisión de informes, art. 134.2), y, sobre todo, en la legislación referida al procedimiento administrativo común (art. 149.1.18 CE), donde deberán regularse nuevas fórmulas de procedimiento conjuntos (piénsese, por ejemplo, en el trazado de una autopista, materia en la que las intervenciones de diferentes Administraciones están urgiendo su integración en un procedimiento único y conjunto, al modo de los de análogo signo contemplados en el Ordenamiento federal alemán). 
e) Una técnica de especial contundencia y que, ésta sí, cuenta con tradición en el Derecho local español es la disolución de los órganos de las Corporaciones locales, si bien el artículo 61 (que la LB dedica a este asunto) ha introducido modificaciones para acomodar esta medida a la nueva formulación de la autonomía local. La competencia corresponde al Consejo de Ministros, que puede actuar a iniciativa propia y con conocimiento del Consejo de Gobierno de la Comunidad Autónoma o simplemente a solicitud de éste, siempre con el informe previo de la Comisión Nacional de Administración Local (art. 118.1 A de la LB); obsérvese, no obstante, que tal competencia corresponde al tipo de las que la doctrina llama compartidas, pues se exige «en todo caso previo acuerdo favorable del Senado». Por lo demás, sólo procede la disolución "en el supuesto de gestión gravemente dañosa para los intereses generales que supongan el incumplimiento de obligaciones constitucionales", fórmula que supone un acotamiento de gran precisión en relación con las utilizadas en el Derecho anterior que invocaba únicamente el daño "para los intereses generales o los de la respectiva Entidad local».

Procede, en tal caso, la convocatoria de elecciones parciales, salvo que, por la fecha en que ésta debiera constituirse, el mandato de la misma hubiese de resultar inferior a un año. Una Comisión gestora, nombrada por la Diputación (o, en el caso de Comunidades Autónomas uniprovinciales, por el órgano competente de ésta), se ocupa, en el ínterin, de la administración ordinaria de la Corporación (art. 183, Ley electoral).

Otro es el supuesto previsto en la Ley Orgánica Electoral General según el que, cuando el número de hecho de corporativos sea inferior a los dos tercios del mínimo legal de miembros de la Corporación (por sucesivas renuncias, por ejemplo, que afecten a toda la lista electoral), procede la designación por la Diputación Provincial (o Comunidad Autónoma uniprovincial) de una Comisión gestora integrada, teniendo en cuenta los resultados de la última elección municipal, por todos los miembros de la Corporación que continúen, y completada por personas de adecuada idoneidad o arraigo (art. 182).

\section{LA APARICIÓN DEL CONFLICTO: IMPUGNACIÓN DE ACUERDOS Y EJERCICIO DE ACCIONES}

Las profundas modificaciones que se han operado tras la LB en esta materia son de tal calado que sitúan al Derecho español entre los primeros del Derecho comparado que cuentan con técnicas jurídicas más 
depuradas para garantizar la autonomía local. Se ha llegado, como vamos a ver, a una judicialización prácticamente total del sistema, desconocido en los ordenamientos más avanzados, en la tradición histórica española, y que no podía vislumbrarse cuando se planteó el recurso que resuelve la Sentencia del Tribunal Constitucional de 2 de abril de 1981 (fund. 12).

Veamos, en primer lugar, los aspectós más relevantes del nuevo sistema.

Los actos y acuerdos de las Corporaciones locales pueden ser impugnados por:

a) Los interesados o, en general, los legitimados, de acuerdo con las reglas del proceso contencioso-administrativo; los actos que ponen fin a la vía administrativa se precisan en el artículo 52.2.LB.

b) La Administración del Estado y de las Comunidades Autónomas, tal como veremos.

c) Los miembros de las Corporaciones que hubieren votado en contra de tales acuerdos o actos.

Vimos también en su momento cómo los entes locales territoriales pueden impugnar disposiciones y actos de las Administraciones del Estado o de las Comunidades Autónomas, así como promover la impugnación ante el Tribunal Constitucional de leyes cuando tales normas se entiende que infringen la garantía institucional de la autonomía local (art. 63.2 y 3). Nótese que esta fórmula de promover recursos de inconstitucionalidad, cuya interposición ha de respaldar la Comisión Nacional de Administración Local o, al menos, la representación de las Entidades locales presente en la misma (en los términos del artículo 119 LB), es la única vía permitida por un Ordenamiento constitucional como el nuestro, que no admite la legitimación de las Corporaciones locales para la impugnación directa de disposiciones legales (salvo por la vía compleja, defendida por algún sector doctrinal, del recurso de amparo); al contrario, por cierto, de lo que ocurre en otros ordenamientos como es el caso notoriamente del germano occidental, en el seno del cual las Corporaciones locales pueden acudir directamente, y de hecho acuden con frecuencia, ante los Tribunales constitucionales.

Los artículos 65 y 66 distinguen dos supuestos:

a) Actos o acuerdos que infringen el ordenamiento jurídico. Cuando, a juicio de la Administración del Estado o de la Comunidad Autónoma, éstos se produzcan, puede ser requerida la Corporación local en el plazo de quince días (contados a partir de la recepción de la comunicación del acuerdo), motivadamente y citando la normativa que se estime vulnerada, con el objeto de que ésta anule dicho acto o 
acuerdo. Si la Corporación no reacciona en el plazo señalado en el requerimiento, procede la impugnación ante la jurisdicción contenciosoadministrativa en el plazo de dos meses siguientes al día en que venza el plazo establecido en el requerimiento (art. 215.4 ROF). También puede omitirse este trámite del requerimiento y procederse directamente a la impugnación ante los Tribunales, también en el plazo de dos meses siguientes al día de la recepción de la comunicación del acto o acuerdo (art. 215.5 ROF).

b) Actos y acuerdos que menoscaben competencias del Estado o de las Comunidades Autónomas, interfieran su ejercicio o excedan de su competencia. Estos actos así viciados pueden ser impugnados directamente (la expresión "sin necesidad de previo requerimiento" quedó en el precepto sin el sentido que le otorgaba el hecho de que, en el proyecto del Gobierno, el artículo 65 exigía siempre requerimiento) ante los Tribunales, en el plazo de quince días. Puede, con la impugnación, pedirse la suspensión del acto o acuerdo impugnado, razonando el interés superior afectado; el Tribunal (o el Juez unipersonal de los contencioso, de acuerdo con las previsiones de los arts. 90 y sigs. de la Ley Orgánica del Poder Judicial), si la estima fundada, acordará la suspensión en el primer trámite subsiguiente a la presentación de la impugnación; suspensión que puede alzarse (como, por lo demás, ocurre en el régimen general de la suspensión) en cualquier momento total o parcialmente (tramitándose el incidente en pieza separada en el que existe trámite de audiencia de la Administración demandante) cuando, de persistir la suspensión, «hubiera de derivarse perjuicio al interés local no justificado por las exigencias del interés general o comunitario hecho valer en la impugnación».

La Ley catalana altera algún plazo (el requerimiento procede en el de dos meses, lo cual modifica la LB y debe ser atendido en el de treinta días, precisión que no está en la LB) y la Ley foral de Navarra de 17 de abril de 1986 introduce, además, el control del interés general de las actuaciones de los entes locales que se refieran a bienes y derechos; no puede tal control, tener por objeto «juzgar sobre la oportunidad del acuerdo adoptado por la Entidad local, sino que tratará sobre su adecuación o no a los intereses generales que puedan concurrir en la decisión de aquélla", fórmula ésta acorde con la Ley de Amejoramiento del Fuero (art. 46.2), pero de dudosa constitucionalidad.

Por último, la LB prevé la suspensión en vía gubernativa (al estilo de nuestras antiguas leyes de régimen local) sólo cuando «una Entidad local adoptara actos o acuerdos que atenten gravemente el interés general de Españan, supuesto en el que el Delegado del Gobierno, previo 
requerimiento al Presidente de la Corporación, y en el caso de no ser atendido, podrá suspenderlos y adoptar las medidas pertinentes a la protección de dicho interés, debiendo impugnarlos en el plazo de diez días, desde la suspensión, ante la jurisdicción contencioso-administrativa.

El órgano competente para la impugnación en los supuestos de los artículos 65 y 66 LB, en el ámbito de la Administración del Estado, será el Gobernador civil, de acuerdo con la Sentencia del Tribunal Supremo de 22 de julio de 1983 y en el de la Administración autonómica, el que determinen sus propias normas.

El procedimiento contencioso a seguir es el general de los artículos 52 y siguientes de la LJCA (la futura reforma de esta ley deberá articular un proceso especial conectado con estas técnicas de la legislación local), quedando reservado el artículo 118 LJCA sólo para el supuesto del artículo 67 LB.

Estos instrumentos de impugnación de acuerdos establecidos en la LB desplazan cualesquiera otros previstos en leyes sectoriales (por ejemplo, el del art. 186.2 de la Ley del Suelo) como ha reconocido la Sentencia del T. C. de 27 de febrero de 1987 al definir a la LB como parámetro de constitucionalidad (véase su último fundamento jurídico), y cuya explicación profunda hay que buscar en la idea del papel o función que cumple una determinada ley en el entero sistema jurídico. Es claro que la LB tiene un cometido central por imperativo del artículo 149.1.18 CE, lo que le proporciona un mayor poder de impregnación del orden jurídico que no logran explicar ni el tradicional principio de jerarquía ni el más moderno de la competencia.

\section{ESTATUTO DE SUS MIEMBROS}

El número de miembros de las Corporaciones locales empieza en cinco para los Ayuntamientos, once para los Consejos insulares y veinticinco para las Diputaciones, aumentando en función de las cifras de población (que el Gobierno declara oficiales por Decreto. Así por ejemplo, el 3114/1981, de 27 de noviembre).

El procedimiento para su elección es distinto, según se trate de concejales o diputados provinciales. Los concejales son elegidos en listas electorales de forma directa por los ciudadanos, con arreglo al sistema proporcional de Hondt o de cociente más alto, sin tener en cuenta aquellas candidaturas que no obtengan, por lo menos, el $5 \%$ de los votos emitidos en la circunscripción. Aunque, en efecto, los concejales son elegidos dentro de la lista de un partido (o de una coalición), la expul- 
sión del partido no supone el cese en el cargo público representativo al que se accede en virtud del sufragio. Esta argumentación no puede aplicarse, sin embargo, al Alcalde, "ya que no puede entenderse que se ha vulnerado el derecho de los ciudadanos a participar en los asuntos públicos por medio de representantes elegidos por sufragio universal, puesto que la elección de Alcalde es de segundo grado" (Sent. de amparo del T. C. de 4 de febrero de 1983).

El Alcalde se elige, como nos consta, entre los concejales que encabecen sus correspondientes listas, por mayoría absoluta de los votos de los concejales; si ninguno obtiene mayoría es proclamado el concejal que encabece la lista que haya obtenido mayor número de votos populares en el Municipio, salvo que funcionen en régimen de concejo abierto, donde el Alcalde es elegido por los electores de acuerdo con el sistema mayoritario. Los diputados provinciales se eligen agrupando los concejales por partidos judiciales en la forma que hemos visto (lección 4. ${ }^{a}$ ). Para las elecciones en las entidades de ámbito territorial inferior al Municipio, los miembros de su órgano colegiado se designarán de acuerdo con los resultados de las elecciones para el Ayuntamiento en la Sección o Secciones constitutivas de la circunscripción para la elección del órgano unipersonal, que es, en todo caso, de elección directa.

Son electores los españoles mayores de edad y los residentes extranjeros cuyos respectivos países permitan el voto de los españoles en las elecciones municipales, en los términos de un Tratado.

La duración del mandato local es de cuatro años.

Son ineligibles, además de las personas incluidas en la larga lista que contiene el artículo 6 de la Ley Electoral General (a la que me remito), los deudores directos o subsidiarios de Corporaciones contra quienes se hubiera expedido mandato de apremio por resolución judicial.

Son incompatibles los abogados o procuradores que representen intereses de las Corporaciones locales, sus funcionarios en activo, los directores o asimilados de Cajas de Ahorro, los contratistas o subcontratistas de las propias Corporaciones.

El juramento o promesa del cargo es obligatorio para el Presidente de la Corporación (arts. 18 y 26 TR), y para el resto de los corporativos, por aplicación del régimen general para los cargos públicos (art. 108.6 de la Ley de Régimen Electoral General).

La Ley trata de garantizar la máxima independencia y neutralidad respecto de los intereses privados de los elegidos concejales o diputados. Al efecto, establece, en primer lugar, un sistema de incompatibilidades que acaba de ser reseñado; en segundo lugar, la obligación de 
formular «declaración de sus bienes y de las actividades privadas que les proporcionen o puedan proporcionar ingresos económicos o afecten al ámbito de sus competencias" (art. 75.5 LB), de forma que se hagan constar en un Registro de Intereses, llevado por el Secretario de la Corporación, que no tiene carácter público, pues para tener acceso a los datos en él inscritos habrá que acreditar la condición de interesado legítimo directo (con la incorporación en la LB del Registro de Intereses se remueve el obstáculo que opuso a la creación de un Registro de esta naturaleza el Tribunal Supremo en Sentencia de 27 de mayo de 1985); en fin, las causas de abstención y recusación propios de la legislación del procedimiento administrativo común y de los contratos.

Retribuciones sólo perciben los miembros corporativos que tengan el régimen de dedicación exclusiva, cuyo número y cuantía fija el Pleno, a propuesta del Presidente (arts. 75 LB y 13 ROF); la dedicación a tiempo parcial genera únicamente el abono de las asistencias a sesiones, pero el ROF permite que todos (es decir, también los adscritos al régimen de dedicación exclusiva) puedan percibir estas indemnizaciones por asistencia a sesiones "cuando se trate de órganos rectores de organismos dependientes de la Corporación local que tengan personalidad jurídica independiente, de Consejos de Administración de empresas con capital o control municipal o de Tribunales de pruebas para selección de personas» (art. 13.6 ROF), lo cual constituye una abierta ilegalidad, pues, según la LB, cuando se disfrutan las retribuciones del régimen de dedicación exclusiva, "su percepción será incompatible con la de cualquier otra retribución con cargo a los Presupuestos de las Administraciones públicas y de los entes, organismos y empresas de ellas dependientes» (art. 75.1 LB).

Aquellos corporativos que tengan la condición de funcionarios se acogen a la situación de servicios especiales mientras dure su mandato (art. 74 LB).

El derecho a obtener del Presidente de la Entidad "cuantos antecedentes, datos o informaciones obren en poder de los servicios de la Corporación y resulten precisos para el desarrollo de la función" (art. 77 LB) es minuciosamente regulado y desarrollado en el ROF. Sólo podrá denegarse por resolución o acuerdo motivado, y opera el silencio, con carácter positivo, por el simple transcurso del plazo de cinco días. No se precisa autorización cuando se trata de miembros corporativos específicamente responsables de la materia cuya información se pretende, así como cuando se trate de materias que correspondan a asuntos que hayan de ser tratados en el órgano colegiado de que el peticionario forme parte o sea información accesible a cualquier ciudadano. Nor- 
malmente, la consulta de los expedientes o antecedentes habrá de hacerse en los archivos o dependencias municipales o provinciales.

Todo este cuidado y matizado sistema de garantías ha intentado ser arruinado por la Resolución interpretativa dè la Dirección General de Administración Local (BOE de 28 de enero de 1987) al decir que "todo ello se entiende sin perjuicio de las normas u órdenes de funcionamiento interno de dichos servicios que haya podido establecer el Alcalde o Presidente como Director de la Administración de la Entidad Local y jefe superior de todo su personal, o por aquellos miembros de la Corporación que ostenten delegaciones en estos ámbitos». Felizmente, el rango del instrumento donde se contiene esta excepción, que desmonta todo el sistema, no afecta al texto ni de la LB ni del ROF.

Sólo son responsables de los acuerdos de las Corporaciones locales los miembros de las mismas que los hubiesen votado favorablemente; la responsabilidad civil o la penal de los corporativos se exigirá ante los Tribunales de Justicia competentes. Los policías locales (arts. 8 y 52 de la Ley Orgánica de Fuerzas y Cuerpos de Seguridad del Estado de 13 de marzo de 1986) tienen fuero especial, lo que resulta de más que dudosa constitucionalidad.

Estas reglas reseñadas - sistema de elección, retribuciones, incompatibilidades, derechos, responsabilidad - tienen carácter básico; ello no excluye que el Reglamento orgánico pueda regular o modular algunos aspectos. Tal ocurre, por ejemplo, con la potestad sancionadora de los Presidentes de las Corporaciones (recogida en el art. 78.4 LB), cuya formulación admite la gradación de las sanciones y cuyos límites, aun estando señalados en el artículo 73 TR (por no tener contenido básico), admiten una regulación distinta en el ejercicio por la Corporación local de su potestad reglamentaria (así lo entiende igualmente la Resolución de la D. G. de Administración, en su apartado 8).

\section{INFORMACIÓN Y PARTICIPACIÓN CIUDADANAS}

El derecho a la información de los asuntos municipales de los ciudadanos (de acuerdo con la terminología empleada por la LB, art. 70.3, y no los vecinos, restricción que quiere imponer sin fundamento el ROF) alcanza a uobtener copias y certificaciones acreditativas de los acuerdos de las Corporaciones locales y sus actividades", en la forma que ya se ha explicado.

Cuando el ciudadano tiene, además, la condición de interesado en el procedimiento, tiene el derecho a la notificación en los términos de la legislación de procedimiento común, y, cuando se trate de una norma 
de carácter general, procede su publicación. Tal ocurre con las Ordenanzas, los Presupuestos y las normas de los Planes urbanísticos que han de aparecer en el Boletín Oficial de la Provincia correspondiente, lo que supone, sobre todo para las normas urbanísticas, una rectificación importante del sistema de publicación anterior (contenido én la Ley del Suelo y el Reglamento de Planeamiento, art. 164 y sigs.).

El artículo 231 ROF contiene alguna precisión referida a los supuestos en que el peticionario "formule una propuesta de actuación municipal", previsión que hay que conectar lógicamente con el derecho de los vecinos a que se refiere el artículo 18.1.g LB, que ya ha sido expuesto. En este caso puede llegarse incluso a requerir la presencia del autor de la propuesta en la sesión del órgano colegiado para explicarla y defenderla personalmente.

El especial protagonismo que atribuye el ROF a las asociaciones de vecinos es de tal magnitud que llega incluso a olvidar a los sujetos individualmente considerados, de forma que éstos no pueden prácticamente participar sino a través de las asociaciones, lo cual resulta ilegal, pues «las Corporaciones locales facilitarán la más amplia información sobre su actividad y la participación de todos los ciudadanos en la vida local» (art. 69.2 LB) y el TC se ha preguntado hasta qué punto es constitucional exigir el cauce asociativo, para responder que, como sostienen unánimemente los Tribunales Constitucionales alemán e italiano, el derecho de asociación comprende no sólo, en su forma positiva, el derecho de asociarse, sino también, en su faceta negativa, el derecho de no asociarse (Sent. 13 de febrero de 1981). A las asociaciones, que pueden llegar a ser declaradas de utilidad pública (art. 72 LB) siempre que se hallen inscritas en el Registro Municipal de Asociaciones Vecinales (art. $236 \mathrm{ROF}$ ), les está permitido:

a) Participar en los Plenos, siempre que se solicite al Alcalde, de forma que la posición de su portavoz pueda explicarse antes de la lectura, debate y votación del asunto.

b) Participar en los Consejos sectoriales, teniendo en cuenta su especialización sectorial y su representatividad ("lo que, sin duda, implica, a la hora de valorar estas circunstancias, en aquellos Municipios en que existe un gran número de asociaciones, el establecimiento, por cada Corporación, de los requisitos que deben reunir tales asociaciones para acceder a los instrumentos de participación", según aclara la Resolución de la D. G. de Administración Local).

c) Recibir en su domicilio la convocatoria, el orden del día de los órganos colegiados y las publicaciones periódicas municipales relacionadas con su fin social. 
d) Recibir subvenciones; y

e) Usar los medios públicos municipales, de acuerdo con la ordenación que hagan los Ayuntamientos.

Resulta sorprendente que el ROF piense sólo en el asociacionismo municipal (el Alcalde, art. 228; el Ayuntamiento, art. 232; la información municipal, art. 234; el Registro municipal de asociaciones, etc.) cuando el precepto legal de que trae causa habla sin más de las Corporaciones locales (art. $72 \mathrm{LB}$ ).

Un instrumento nuevo en la democracia municipal que, por cierto, está siendo de frecuente utilización, es el de los referéndum municipales, que puede convocar el Alcalde, previo acuerdo por mayoría absoluta del Pleno y autorización del Gobierno de la Nación, referidos únicamente a asuntos de la competencia propia municipal y de carácter local que sean de especial relevancia para los intereses de los vecinos, con excepción de los relativos a las Haciendas locales. A falta de legislación autonómica se aplica la legislación reguladora de las distintas modalidades del referéndum (Ley Orgánica de 18 de enero de 1980). La Ley catalana ( 2 de abril de 1987) obliga al Alcalde a someter la petición del referéndum al Pleno, cuando ésta venga firmada por un número determinado de vecinos (art. 144, que no contiene, por lo demás, un régimen pormenorizado de este tipo de consultas). 